\title{
Postpubertal Sex Differentiation of Forebrain Structures and Functions Depend on Transforming Growth Factor- $\alpha$
}

\author{
Kyoko Koshibu, ${ }^{1}$ Eric T. Ahrens, ${ }^{2}$ and Pat Levitt ${ }^{3}$ \\ ${ }^{1}$ Department of Neurobiology and Center for Neural Basis of Cognition, University of Pittsburgh, Pittsburgh, Pennsylvania 15261, ${ }^{2}$ Department of Biological \\ Sciences and Pittsburgh Nuclear Magnetic Resonance Center for Biomedical Research, Carnegie Mellon University, Pittsburgh, Pennsylvania 15213, and \\ ${ }^{3}$ Vanderbilt Kennedy Center for Research on Human Development and Department of Pharmacology, Vanderbilt University, Nashville, Tennessee 37203
}

\begin{abstract}
Sex- and age-associated deficits in brain structure and behavior are reported in a number of neuropsychiatric disorders. Although genetic and environmental factors are thought to contribute to the pathogenesis, there are only few examples in clinical or experimental systems that have identified specific causes. Here, we report that transforming growth factor- $\alpha$ (TGF $\alpha$ ) may regulate sex- and age-dependent development of forebrain structures and associated neural functions after puberty. Waved-1 (Wa-1) mice inherit an autosomal recessive, spontaneous mutation that results in a postnatal reduction in TGF $\alpha$ gene expression. The assessment of forebrain structures using a three-dimensional magnetic resonance microscopy indicated ventricular enlargement and striatal reduction in both male and female Wa-1 adult mice, with $\mathrm{Wa}-1$ males exhibiting a more severe phenotype. In contrast, the hippocampal volume was reduced only in adult Wa-1 males. Similarly, behavioral analyses showed impaired auditory and contextual fear learning in adult $W a-1$ males only, whereas abnormal stress response was expressed by both male and female adult $\mathrm{Wa}-1$ mice. Interestingly, all behavioral deficits were absent before full sexual maturation, despite some slight forebrain structural abnormalities. These results suggest that TGF $\alpha$ may regulate postpubertal, sex differentiation in ventricular and periventricular anatomy and associated behavior, affecting predominantly males. In particular, the adult male-specific reduction in hippocampal volume may reflect an age- and sex-specific regulation of stress homeostasis and fear learning. Furthermore, a lack of a behavioral phenotype, despite anatomical alterations in peripubertal $\mathrm{Wa}-1 \mathrm{mice}$, suggests that analysis of certain neuroanatomical features at puberty may predict neurobehavioral deficits in adulthood.
\end{abstract}

Key words: fear conditioning; stress; magnetic resonance imaging; hippocampus; sex; puberty

\section{Introduction}

Sex and age are factors that may contribute to the pathophysiology of specific neuropsychiatric disorders. For example, the average age of onset of schizophrenia is between adolescence and adulthood (for review, see Lewis and Lieberman, 2000). Males show an earlier onset of schizophrenic symptoms and exhibit more severe forebrain abnormalities and poorer clinical outcome than females (Nopoulos et al., 1997; Gur et al., 2004). Other neurodevelopmental disorders, such as autism, are more prevalent in males than in females, with no X- or Y-linked patterns of inheritance (for review, see Rutter et al., 2003). The biological

\footnotetext{
Received Nov. 3, 2004; revised Feb. 27, 2005; accepted March 2, 2005.

This work was supported in part by National Science Foundation Integrative Graduate Education and Research Traineeship Predoctoral Grant DGE-9987588 and the Center for the Neural Basis of Cognition at the University of Pittsburgh (K.K.) and National Institutes of Health Grant MH45507 and National Institute of Child Health and Human Development Grant HD015052 (P.L.). E.T.A. is supported by National Institutes of Health Grants R01-EB003453, P41-EB001977, and P50-AR049617. We thank Drs. Allan Sampson, Mark Gamalo, Jennifer Blackford, and Warren Lambert for expert statistical consulting and Drs. Edda Thiels, Laura Lillien, Paula Monaghan-Nichols, Karl Kandler, Gregg Stanwood, Daniel Campbell, and Elizabeth Powell for valuable scientific discussions. We also thank Raymond Johnson for the technical assistance in HPLC analyses.

Correspondence should be addressed to either of the following: Pat Levitt, Vanderbilt Kennedy Center for Research on Human Development, Vanderbilt University, Box 40 Peabody, 230 Appleton Place, Nashville, TN 37203, E-mail: pat.levitt@vanderbilt.edu; or Kyoko Koshibu, Swiss Federal Institute of Technology/University of Zurich, Brain Research Institute, Bau 55 H38, Winterthuerstrasse 190, CH-8057, Zurich, Switzerland, E-mail: koshibu@hifo.unizh.ch.

DOI:10.1523/JNEUROSCI.0175-05.2005

Copyright $\odot 2005$ Society for Neuroscience $\quad$ 0270-6474/05/253870-11\$15.00/0
}

mechanisms responsible for these sex- and age-associated neural disruptions, however, are as yet unknown.

Interestingly, manipulations of transforming growth factor- $\alpha$ ( TGF $\alpha$ ) expression result in sex- and age-dependent behavioral and brain anatomical disturbances. TGF $\alpha$ is a member of the ErbB receptor tyrosine kinases, regulating developmental processes, including the onset of female puberty (Ma et al., 1992). Its expression is developmentally regulated, sensitive to gonadal steroids, and increases at approximately puberty in female rat and primate hypothalamus (Ma et al., 1994a,b). Waved-1 (Wa-1) is an autosomal recessive mouse carrying mutation(s) in $T G F \alpha$ gene (Crew, 1933; Fowler et al., 1993). Similar to other TGF $\alpha$ and erbB1 mutant mice, $\mathrm{Wa}-1$ mice show abnormal hair follicles, resulting in wavy hair, and delayed prenatal eyelid fusion (Luetteke et al., 1993, 1994; Mann et al., 1993). In Wa-1 males, TGF $\alpha$ transcript and protein levels are reduced throughout postnatal development (Weickert and Blum, 1995; Berkowitz et al., 1996), which results in enlarged lateral ventricles and compromised contextual fear conditioning in adulthood but not during prepubescence (Burrows et al., 2000). These studies (except for Weickert and Blum, 1995) were conducted using the original strain of Wa-1 mice, which had a mixed strain background with additional mutations (Crew, 1933; Fowler et al., 1993). Other studies have shown that the overexpression of TGF $\alpha$ results in sex-dependent disruptions in stress behavior (Hilakivi-Clarke et al., 1992, 1993). 
To clarify the function of TGF $\alpha$ in establishing the sex- and age-specific anatomical and behavioral properties during development, a more recent strain of $W a-1$ on a C57BL/6J background carrying a sole mutation in TGF $\alpha$ gene was examined. Male and female adult and pubertal Wa-1 mice were studied. The hippocampus, amygdala, striatum, and lateral and third ventricle volumes and surface areas were determined using threedimensional (3D) magnetic resonance microscopy (MRM). These forebrain structures have been implicated in sexual dimorphism (Filipek et al., 1994; Caviness et al., 1996; Giedd et al., 1997), neuropsychiatric disorders (Weinberger, 1995; Chetelat and Baron, 2003; MacQueen et al., 2003), and stress and learning behavior (Luine, 2002). We also assessed memory functions by using delay fear conditioning paradigms. Because memory can be negatively or positively affected by stress in a sex-specific manner (Luine, 2002; Bowman et al., 2003), we also assessed stress responses. The data indicate that TGF $\alpha$ regulates postpubertal development of selective forebrain structures predominantly in males, which is reflected in sex- and age-dependent memory and stress regulation impairment in $\mathrm{Wa}-1$ mice.

\section{Materials and Methods}

Animals. Male and female control and $W a-1$ C57BL/6J mice were used for all of the experiments. Heterozygous mating pairs were purchased from The Jackson Laboratory (Bar Harbor, ME) to establish the colony. This strain of $\mathrm{Wa}-1$ has been backcrossed over 12 generations to C57BL/6J strain by The Jackson Laboratory and our laboratory, creating a congenic background. During this process, other mutations present in the original strain of $W a-1$ (APB/Le a/a Tyrpl ${ }^{\mathrm{b}} / \mathrm{Tyrpl}^{\mathrm{b}} \mathrm{bt} / \mathrm{bt} \mathrm{p} / \mathrm{p} \mathrm{Bmp5}{ }^{\mathrm{SE}} /$ $\mathrm{Bmp} 5^{\mathrm{SE}}$ ) were eliminated (The Jackson Laboratory). All studies used animals obtained through timed matings. The control group included wild-type and heterozygous mice, because the latter did not show any difference from the wild type in any of the parameters measured. Although estrous phase was monitored daily by recording vaginal color and opening in all postpubertal females, none of the parameters were greatly affected by the estrous cycle (data not shown). The behavioral analyses, plasma corticosterone assay, and MRM were conducted in adult (3-4.5 months) and pubertal (1-1.5 months) mice. Only adult groups were used for plasma catecholamine analyses. Mice used for behavioral analyses were weighed at 1 or 3-4.5 months. Although there were age- and sexdependent differences (adults heavier than pubertal mice; males heavier than females), there was no difference between control and $\mathrm{Wa}-1$ body weight (data not shown). Mice used for the plasma catecholamine analyses and MRM analyses were not used previously in behavioral tests.

All mice were group housed and maintained in a central facility at University of Pittsburgh School of Medicine in a controlled environment with a $12 \mathrm{~h}$ light/dark cycle and access to food and water ad libitum. Experiments were performed in accordance with the guidelines provided by University of Pittsburgh Institutional Animal Care and Use Committees and the National Institute of Health Guide for the Care and Use of Laboratory Animals.

Genotyping using simple sequence-repeat PCR. Because $W a-1$ is a spontaneous mutation and the exact site(s) of genomic mutation(s) is unknown, a simple sequence-repeat (SSR) PCR assay was developed to distinguish wild-type and mutant mice. SSRs are microsatellite sequences flanking a gene that vary in the number of repeats among different strains of mice (for review, see Weber, 1990; Weber et al., 1990). Because $\mathrm{Wa}-1$ has been fully backcrossed to the C57BL/6J background, which is a different strain than the original strain of $\mathrm{Wa}-1$, it was possible to genotype the mice by PCR amplification of the SSRs surrounding the $T G F \alpha$ gene. This method was used to map and genotype other spontaneous mutations in mice, tottering and Purkinje cell degeneration (Campbell and Hess, 1997; Campbell et al., 1999).

In brief, 3-5 $\mathrm{mm}$ tail was clipped and digested in non-ionic detergent buffer containing $50 \mathrm{~mm} \mathrm{KCl}, 10 \mathrm{~mm}$ Tris-Cl, $\mathrm{pH}$ 8.3, 2 mм $\mathrm{MgCl}_{2}, 0.1$ $\mathrm{mg} / \mathrm{ml}$ gelatin, $0.45 \% \mathrm{NP}-40,0.45 \%$ Tween 20 , and $1.5 \mu \mathrm{lof} 10 \mathrm{mg} / \mathrm{ml}$ proteinase $\mathrm{K}$, at $52-54^{\circ} \mathrm{C}$ overnight. The digested tails were heat inacti- vated at $95^{\circ} \mathrm{C}$ for $10 \mathrm{~min}$. The PCR reaction contained $0.68 \mu \mathrm{l}$ of forward and $0.68 \mu \mathrm{l}$ of reverse MapPair primers (Research Genetics, Huntsville, $\mathrm{AL}$ ), $3 \mu \mathrm{l}$ of $10 \times$ ThermoPol Reaction Buffer (New England Biolabs, Beverly, MA), $4.8 \mu \mathrm{l}$ of $2.5 \mathrm{~mm}$ dNTP, $0.3 \mu \mathrm{l}$ of Vent (exo-) DNA Polymerase (New England Biolabs), and 1-2 $\mu$ l of tail digest in a total volume of $30 \mu \mathrm{l}$. The PCR program was as follows: $95^{\circ} \mathrm{C}$ for $5 \mathrm{~min}$ for $1 \mathrm{cycle}$, $95^{\circ} \mathrm{C}$ for $30 \mathrm{~s}, 62,60$, or $58^{\circ} \mathrm{C}$ for $1 \mathrm{~min}$, and $72^{\circ} \mathrm{C}$ for $1 \mathrm{~min}$ for 5,10 , and 30 cycles (respectively, for the three annealing temperatures), followed by the final elongation at $72^{\circ} \mathrm{C}$ for $5 \mathrm{~min}$. The PCR products were run on $3.5 \%$ agarose in $1 \times$ TAE $(0.04 \mathrm{M}$ Tris-acetate and $1 \mathrm{~mm}$ EDTA, $\mathrm{pH} 8.0)$ with ethidium bromide and were UV visualized. The MapPairs used were D6Mit8 [0.7-1.3 centimorgans (cM) upstream of TGF $/ \mathrm{Wa}-1$; forward, TGCACAGCAGCTCATTCTCT; reverse, GGAAGGAAGGAGTGGGGTAG] and D6Mit228 (1.1-0.5 cM downstream of TGF $\alpha / W a-1$; forward, GTTCCCAACAAGGTGGCTAA; reverse, GAGCAGTATGCGGCAGATTT). The wild-type C57BL/6J band sizes were 164 bases for D6Mit8 and 108 bases for D6Mit228 MapPairs. The $W a-1$ band sizes were estimated to be $\sim 190$ bases for D6Mit8 and $\sim 130$ bases for D6Mit228 MapPairs. Because $W a-1$ has naturally wavy hair and whiskers from birth to adulthood, the genotype of $\mathrm{Wa}-1$ homozygotes was visually confirmed by this phenotype.

MRM. Data from wild-type mice and detailed methods used for MRM have been published recently (Koshibu et al., 2004). This imaging technique was chosen over traditional histological methods to minimize distortion artifacts produced by the extreme treatment of the brain tissue during fixation, sectioning, and mounting and for the greater accuracy in determining structure volumes. Thus, MRM in intact tissues produces morphometric measurements with less variability compared with histological approaches, permitting a smaller statistical sampling size and a more rapid analysis.

Briefly, male and female control and $W a-1$ C57BL/6J inbred mice at 1 month (puberty) and 3 months (adult) were anesthetized with sodium pentobarbital and then transcardially perfused with $0.9 \% \mathrm{NaCl}$, followed by $4 \%$ formaldehyde/ $1 \%$ glutaraldehyde in PBS, $\mathrm{pH}$ 7.4. Brains were excised from the skull, immersed in fixative, and stored at $4^{\circ} \mathrm{C}$. The digital image of each intact brain specimen was collected using an 11.7 tesla Bruker (Rheinstetten, Germany) AVANCE microimaging system. Two coregistered 3D data sets were acquired for each sample. One data set used a T2/spin-density weighted 3D Fourier transform spin-echo sequence, with a repetition time/echo time $(\mathrm{TR} / \mathrm{TE})=900 / 45 \mathrm{~ms}$. The other data set used a diffusion-weighted 3D Fourier transform pulsedgradient spin-echo sequence (DW-3DFT), with TR/TE $=900 / 20 \mathrm{~ms}$. For the DW-3DFT data sets, diffusion gradients were applied along the rostrocaudal direction with $\delta=5 \mathrm{~ms}, \Delta=15 \mathrm{~ms}$ at a gradient strength of 30 $\mathrm{g} / \mathrm{cm}$. The DW-3DFT data set was particularly useful in segmenting the ventricles because signal from the fluid in these structures was readily dephased by the diffusion gradient pulses. Both data sets were acquired with a $256 \times 128 \times 128$ matrix and then zero filled to $512 \times 256 \times 256$ before Fourier transformation, yielding a final isotropic resolution of $\sim 50 \mu \mathrm{m}$. The total imaging time per data set was $\sim 18 \mathrm{~h}$. Three mice were studied per group. Power analysis verified that this sample size is sufficient to determine statistical significance, given the low inter-animal variance on stereological measures (Koshibu et al., 2004).

Digital segmentation. From the MRM data, the lateral and third ventricles, hippocampus, amygdala, striatum, and total brain were digitally segmented in $3 \mathrm{D}$ in a semiautomated manner using the software AMIRA (TGS, San Diego, CA). Each structure was traced manually in a combination of coronal, horizontal, and sagittal orientations (see Fig. 1). Using AMIRA, the pixel-to-pixel borders were then smoothed in 3D to obtain the most accurate representation of each segmented structure. A 3D surface reconstruction of each structure was then created, and the volume and surface area were calculated as described by Koshibu et al. (2004).

The hippocampal volume included the fornix at the rostral boundary. The amygdala segment was bounded by the bifurcation of ventral corpus callosum anteriorly, the optic tract and ventral horn of the lateral ventricles medially, and extension of the ventral corpus callosum to the ventral cortex lateroventrally. The striatum was segmented in its entirety. An example of segmentation of the respective structures is shown in Figure 1. 
For the total brain, the entire brain was segmented except for olfactory bulbs and the brainstem posterior to the aqueduct.

Behavior. All behavioral experiments, except for stress-induced hyperthermia, were conducted in the afternoon between 2:00 and 6:30 P.M. using a TruScan Photobeam Activity System (Coulbourn Instruments, Allentown, PA). The system consisted of a square arena ( $x, y, z$ dimension $=27,27,38 \mathrm{~cm}$ ) with photobeam frame $(\mathrm{s})$. The infrared light beams crisscrossed every $1.5 \mathrm{~cm}$ in $x-y$ coordinate. This array of infrared beams enabled automated collection of all locomotor activity by a digital analyzer every $0.5 \mathrm{~s}$.

Open-field activity test. To assess general activity and exploratory behavior, mice were placed in a TruScan Photobeam Activity System for 10 $\mathrm{min}$. The total movement time and distance, marginal zone time, stereotypy, and number of rears were determined. The marginal zone was defined as $3.75 \mathrm{~cm}$ from the edges of arena. The stereotypy was defined as movements consisting of three consecutive photobeam crossings of the same photobeam, occurring within $2 \mathrm{~s}$ of each other. The stereotypic activity included repetitive behaviors, such as head bobbing, grooming, and paw licking. Fifteen control males, $12 \mathrm{Wa}-1$ males, 14 control females, and $15 \mathrm{Wa}-1$ females were used for adult groups. Nine control males, eight $\mathrm{Wa}-1$ males, seven control females, and five $W a-1$ females were used for pubertal groups. Two control adult females and one $\mathrm{Wa}-1$ adult female were eliminated from the analysis as outliers, defined as values greater than 2 SDs away from the mean.

Light/dark choice test. The TruScan Photobeam Activity System was divided into light and dark sides by inserting a black box with a small entrance onto one side of the arena. Mice were placed on the brightly lit side of the arena and were left to explore both light and dark sides for 10 min. Total number of entries and time spent on the dark side were calculated to determine anxiety level. Eight control males, $10 \mathrm{Wa}-1$ males, 10 control females, and $9 W a-1$ females were used for adult groups. Six control males, six $\mathrm{Wa}-1$ males, seven control females, and five $W a-1$ females were used for pubertal groups. Two control adult males, two $W a-1$ adult males, one control adult female, and one $W a-1$ adult female were 2 SDs away from the mean and, thus, eliminated from the analysis.

Delay fear conditioning. A shock grid floor with 23 bars $6 \mathrm{~mm}$ apart was inserted in a TruScan Photobeam Activity System, and a speaker was mounted on top of the arena wall. The shock grid floor provided alternating current between the adjacent bars. On the training day, mice were exposed to this arena for $2 \mathrm{~min}$, followed by $30 \mathrm{~s}$ continuous tone $(80 \mathrm{~dB}$, $2000 \mathrm{~Hz}$ ). During the last $2 \mathrm{~s}$ of the tone, an $\sim 0.2 \mathrm{~mA}$ foot shock was given for $2 \mathrm{~s}$. After $1 \mathrm{~min}$, the tone-shock paired training was repeated. A total of three tone-shock paired trials were administered.

Approximately $24 \mathrm{~h}$ later, context learning was assessed. A mouse was placed in the training arena for $5 \mathrm{~min}$, without tone or shock, and its activity was monitored. Associative conditioning to the tone was tested $\sim 1.5-3 \mathrm{~h}$ later. For assessment of tone conditioning, the testing arena was changed to eliminate the contextual learning as follows: (1) removing the shock grid floor, (2) reducing the size of the arena by half, (3) changing the size of the arena, (4) changing the smell of the arena by washing it with lemon-scented detergent, and (5) reducing the light intensity of the testing room. Mice were placed in this new context for 3 min (pre-tone), and then the $80 \mathrm{~dB}, 2000 \mathrm{~Hz}$ tone was sounded continuously for the next $3 \mathrm{~min}$ (tone).

Learning was assessed by determining the freezing response of mice. Lack of movement (i.e., freezing) lasting longer than $1 \mathrm{~s}$ was included in the percentage freezing response calculation (freeze time/total test time $\times 100 \%$ ). The freezing response was analyzed for both training and testing trials. In addition, to assess shock sensitivity, speed of movement during the shock was measured during training (distance moved divided by $2 \mathrm{~s}$ ). Nine control males, $8 \mathrm{Wa}-1$ males, 10 control females, and $8 \mathrm{Wa}-1$ females were used for adult groups. Six control males and five $\mathrm{Wa}-1$ males were used for pubertal groups.

Stress-induced hyperthermia. Stress-induced hyperthermia was conducted as described by Zethof et al. (1994). Mice were individually caged in the late afternoon before the testing day. On the following morning (between 8:30 and 10:30 A.M.), a mouse was held in one hand, and its rectal temperature was measured for $20 \mathrm{~s}$ (T1) using a Thermalert TH-5 apparatus (PhysiTemp, Clifton, NJ). The mouse was then returned to the home cage for $10 \mathrm{~min}$, after which, rectal temperature was measured again for $20 \mathrm{~s}(\mathrm{~T} 2)$. The change in temperature $(\mathrm{dT}=\mathrm{T} 2-\mathrm{T} 1)$ was calculated to determine changes in stress levels. Twenty control males, 8 Wa-1 males, 16 control females, and $16 \mathrm{Wa}-1$ females were used for adult groups. Six control males, five $\mathrm{Wa}-1$ males, six control females, and six Wa-1 females were used for pubertal groups.

Corticosterone radioimmunoassay. Trunk blood samples $(\sim 200-600$ $\mu \mathrm{l})$ were collected in microcentrifuge tubes with $20 \mu \mathrm{l}$ of 1000 United States Pharmacopeial U/ml heparin sodium (American Pharmaceutical Partners, Los Angeles, CA) and placed on ice. Plasma was collected by spinning the samples at $\sim 1500 \times g$ for $15 \mathrm{~min}$ at $4^{\circ} \mathrm{C}$ and stored at $-80^{\circ} \mathrm{C}$. The corticosterone levels were determined using Coat-A-Count Rat Corticosterone kit (Diagnostic Products, Los Angeles, CA) according to the protocol of the manufacturer. For the baseline level, blood was collected after an overnight individual housing with access to food and water ad libitum. For the stressed level, blood was collected immediately after the stress-induced hyperthermia test. The animals were killed by decapitation. All samples were collected in the morning between 8:30 and 10:30 A.M. Twenty control males, $8 \mathrm{Wa}-1$ males, 17 control females, and $15 \mathrm{Wa}-1$ females were used for adult stressed corticosterone measurements. Ten control males, five $\mathrm{Wa}-1$ males, six control females, and five Wa-1 females were used for pubertal stressed levels. For the baseline analyses, 12 control males, $5 \mathrm{Wa}-1$ males, 15 control females, and $8 \mathrm{Wa}-1$ females for the adult groups and three animals each of the pubertal groups were used.

Plasma catecholamine measurements. Biogenic amines were determined by a specific HPLC assay using an Antec Decade (oxidation, 0.7) electrochemical detector and following the method by Lindsey et al. (1998). Briefly, plasma samples were purified and concentrated by adsorption of the amines [adrenaline (A); noradrenalin NA)] to solid alumina $\left(\mathrm{Al}_{2} \mathrm{O}_{3}\right)$ to improve the accuracy of the measurements (Mefford, 1985). Dihydroxybenzylamine (internal standard), Tris buffer, $\mathrm{pH} 8.5$, $100 \mathrm{mg} \mathrm{Al}{ }_{2} \mathrm{O}_{3}$, and $100-200 \mu \mathrm{l}$ of supernatant were mixed for $15 \mathrm{~min}$, and then the buffer was aspirated. The $\mathrm{Al}_{2} \mathrm{O}_{3}$ was washed with distilled water, water was aspirated, and then the amines were desorbed from the $\mathrm{Al}_{2} \mathrm{O}_{3}$ using $125 \mu \mathrm{l}$ of $0.1 \mathrm{~N}$ acetic acid. Twenty to $80 \mathrm{ml}$ of these samples were then injected onto a Waters (Milford, MA) Nova-Pak C18 HPLC column using a Waters $717+$ autosampler. Biogenic amines were eluted with a mobile phase consisting of $89.5 \% 0.1 \mathrm{M}$ TCA, $0.01 \mathrm{M}$ sodium acetate, $0.1 \mu \mathrm{M}$ EDTA, and 10.5\% methanol, $\mathrm{pH}$ 3.8. Solvent was delivered at $0.7 \mathrm{ml} / \mathrm{min}$ using a Waters 515 HPLC pump. A calibration curve was run along with the samples and was used to calibrate the instrument. HPLC control and data acquisition were managed by Millennium 32 software (Waters).

The biogenic amine measurements were normalized to the total protein concentrations, which were determined using BCA Protein Assay kit (Pierce, Rockford, IL) according to the protocol of the manufacturer.

Statistics. When applicable, a $2 \times 2 \times 2$ (age $\times$ sex $\times$ genotype) multivariate generalized linear model (GLM) was used. The main effects of age, sex, and genotype and any interactions among various combinations of these factors were determined by type III sum of squares. In addition, a $2 \times 2$ (age $\times$ genotype) GLM was conducted separately for males and females. A univariate GLM with Tukey's post hoc test was used for HPLC data to detect the genotype effect in males and females separately. Any result indicating $p<0.05$ was considered statistically significant. All data are presented as estimated marginal means \pm SEM.

MRM volumetric comparisons were conducted in three ways: (1) using raw data, (2) using data with total brain volume as a covariant, and (3) using data with total brain volume without the ventricular mass (i.e., solid brain volume) as a covariant. Similarly, surface areas were compared among the groups by using the volumetric measurement of respective structures as a covariant to determine a possible dissociation between volumetric and surface area changes. A lack of covariance between the volume and the surface area is consistent with a possible structural shape distortion. If the surface area is disproportionately larger than the volume, then it may indicate an increased convolution of the surface. Con- 


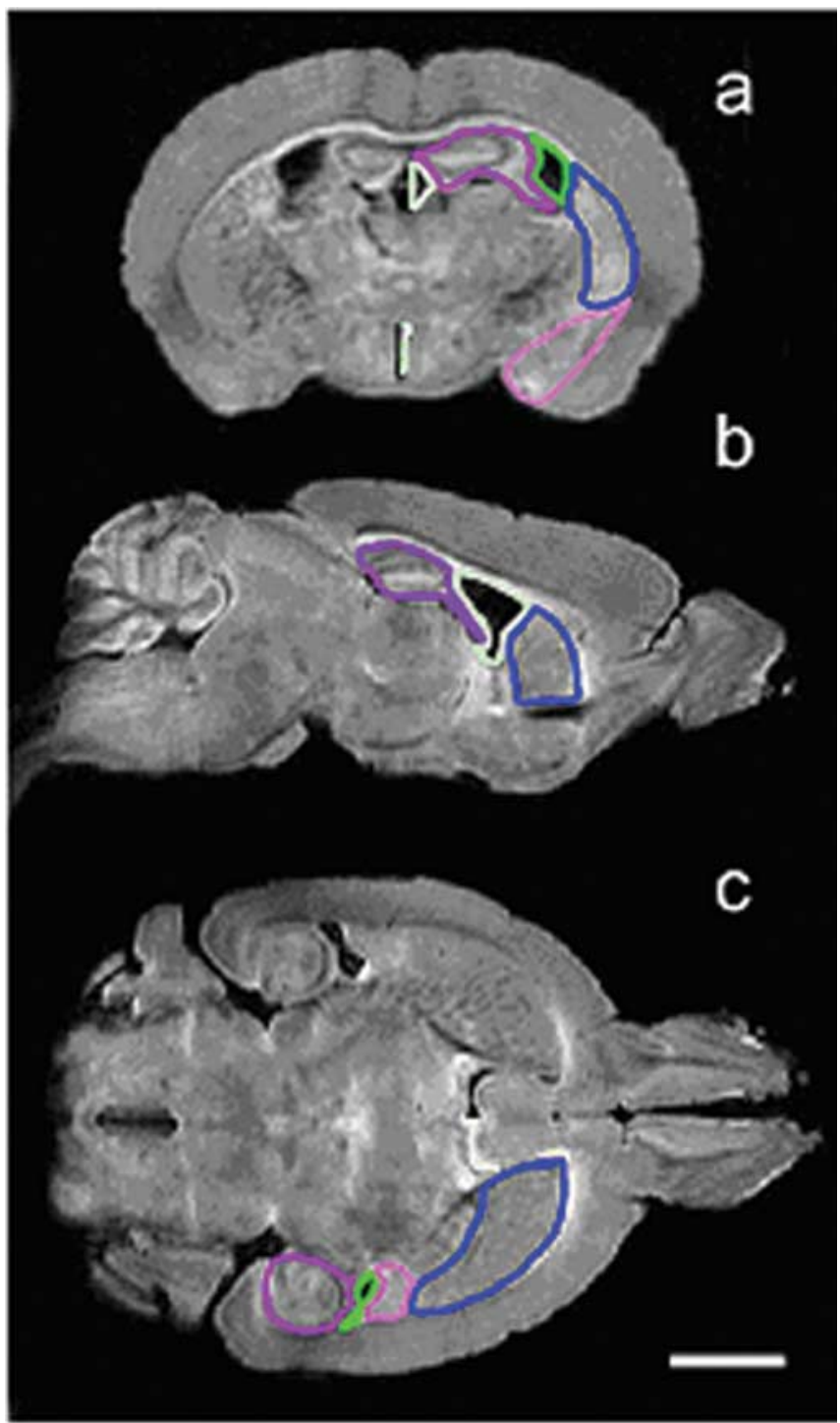

Figure 1. DW-3DFT images of a mouse brain. Single-slice, high-resolution images from a 3-month-old C57BL/6J female mouse are presented in coronal (a), sagittal (b), and horizontal (c) orientations. The boundaries of the segmented structures are outlined for one side of the brain image for lateral ventricle (dark green), third ventricle (light green), hippocampus (purple), striatum (blue), and amygdala (pink). Scale bar, $2 \mathrm{~mm}$.

versely, if the surface area is disproportionately reduced compared with the volume, a smoother surface may be present.

For fear conditioning results, the context, pre-tone, and tone freezing responses were assessed by using the initial freezing response during the first 2 min of training as a covariant to normalize for any general activity differences. For tone learning, pre-tone was used as a covariant to normalize for the differences in pre-tone freezing responses. Similarly, the stressed corticosterone level was normalized to the baseline corticosterone level by taking the baseline corticosterone as a covariant. Pearson's correlation test was conducted to test possible correlation between stress response and fear learning results.

\section{Results}

\section{Forebrain anatomy analyses using MRM}

The MRM methods used in this study provide very-high resolution images that allow clear identification of the subcortical structures (Fig. 1) (Koshibu et al., 2004). Representative single coronal slices taken from the DW-3DFT volumetric data sets are shown for the adult groups in Figure 2. A general enlargement of the lateral and third ventricles (hypotensive areas within the brain parenchyma) is clearly evident in adult females (Fig. $2 c, d$ ) compared with adult males (Fig. $2 a, b$ ) in the raw image data. Furthermore, both male and female adult $W a-1$ (Fig. $2 b, d$, respectively) show enlarged ventricles compared with their respective controls (Fig. 2a,c). Because subtle changes in other structures cannot be determined at this level of analysis, 3D segmentation and reconstruction of all of the structures were conducted.

\section{General developmental and sex-dependent changes in the forebrain structures in combined wild-type and $W a-1$ population}

As expected, the total brain volume is larger at 3 months than at 1 month in general (Fig. $3 f$ ). The developmental enlargement of structures, proportional to the total brain growth, is observed in both male and female hippocampus (Fig. $3 c$ ) and female lateral ventricles (Fig. $3 a$ ). In contrast, the striatum shows disproportionate reduction ( $p=0.005)$, and the amygdala shows disproportionate enlargement $(p<0.001)$ in both sexes when normalized to the total brain growth. Reduced surface areas are detected in lateral $(p=0.023)$ and third $(p=0.036)$ ventricles and hippocampus $(p=0.016)$ at 3 months compared with 1 month despite their increased respective volumes, suggesting a smoother surface of these structures in adult compared with pubertal mouse brains (compare Fig. $3 a-c$ with supplemental Fig. $1 a-c$, available at www.jneurosci.org as supplemental material). In contrast, the increased surface area in amygdala and for total brain at 3 months compared with 1 month (supplemental Fig. $1 e, f$, available at www.jneurosci.org as supplemental material) is proportional to their respective volumetric changes (Fig. 3e,f), indicating no shape distortions in these structures.

The robust differences between males and females also are observed in specific forebrain structure volumes. The lateral $(p=0.002)$ and third ( $p=0.018)$ ventricles are larger (Fig. $3 a, b$, respectively), whereas the amygdala is smaller $(p=0.002)$ (Fig. $3 e$ ) in females compared with males in general. These changes are not attributable to the differences in total brain volume between males and females. Larger lateral ventricles in females compared with the males are mainly attributable to the ventricular enlargement in adult females and not attributable to the sex differences in pubertal mice (Fig. 3a). The enlarged ventricles in females can be visually confirmed in the $3 \mathrm{D}$ reconstructions shown in Figure 4 [compare $a, b$ (males) with $c, d$ (females)]. The opposing volumetric changes in the lateral ventricle and amygdala indicate a possible encroaching of the lateral ventricles on the amygdala. No sex-dependent shape distortions were detected in any of the forebrain structures analyzed.

\section{Sex-dependent developmental changes in forebrain structures of $\mathrm{Wa}-1$}

An enlargement of the lateral and third ventricular volumes is observed in adult $\mathrm{Wa}-1$ (Fig. 4), whereas a slight reduction in these volumes is detected in pubertal $W a-1$ compared with the control groups (Fig. $5 a, b$ ). These ventricular volumetric changes are more pronounced in males than in females. The pubertal $W a-1$ males show 17 and 32\% reductions in lateral and third ventricular volumes, respectively, and 76\% enlargement in adult lateral ventricular volume compared with the control males. In contrast, the pubertal $W a-1$ females show a $5 \%$ reduction in lateral ventricular volume and $47 \%$ enlargement in adult lateral ventricular volume. The changes in adult third ventricular volumes are approximately the same between male and female 
a

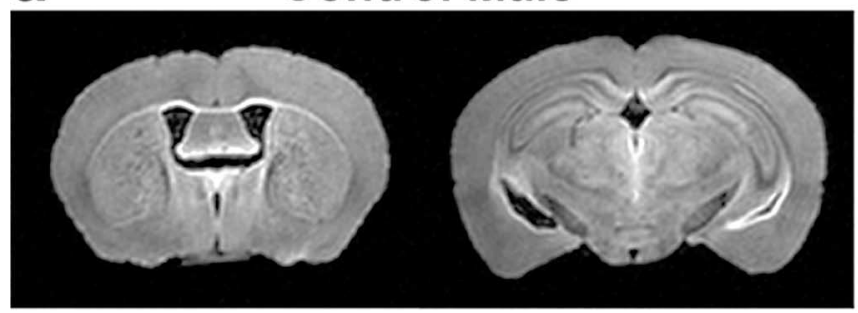

b

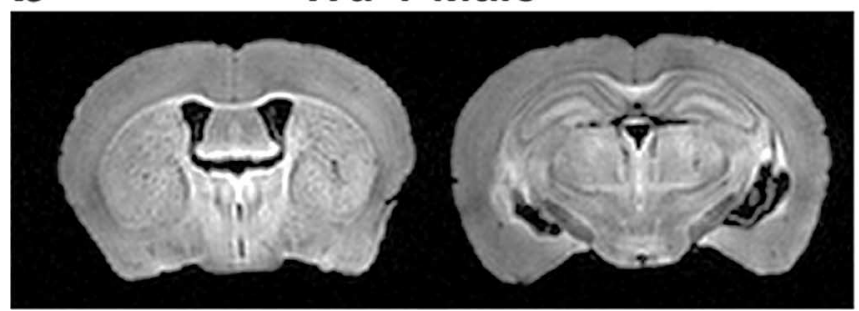

\section{Control Female}

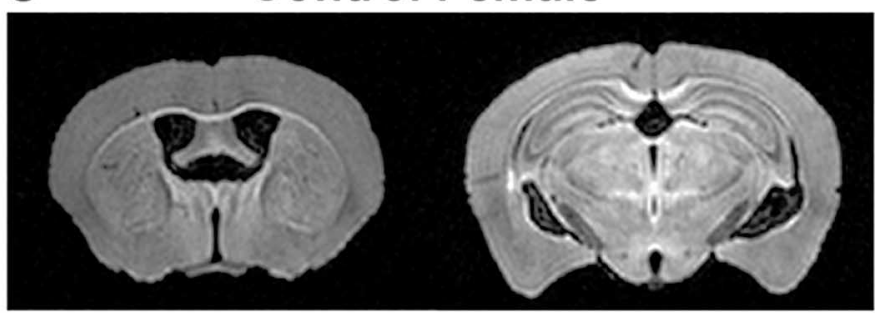

d

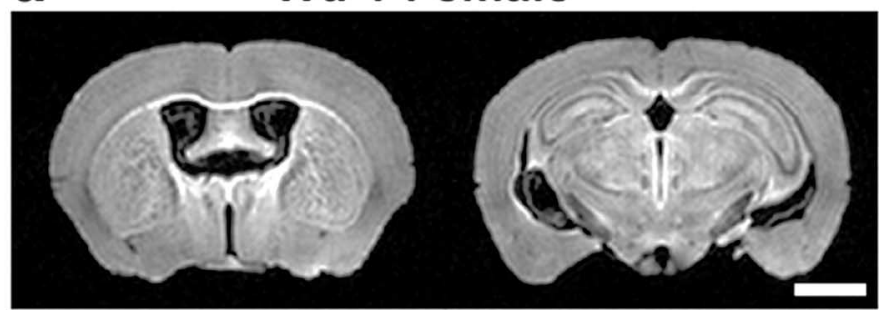

Figure 2. Coronal images from DW-3DFT data sets in adult mice. Representative coronal images for control males ( $\boldsymbol{a})$, Wa- 1 males $(\boldsymbol{b})$, control females $(\boldsymbol{c})$, and Wa- 1 females $(\boldsymbol{d})$ are shown. The lateral and third ventricles (hypointense areas within the brain) are enlarged in females $(\boldsymbol{c}, \boldsymbol{d})$ compared with males $(\boldsymbol{a}, \boldsymbol{b})$ in general. The ventricles are larger in Wa-1 $(\boldsymbol{b}, \boldsymbol{d})$ than in controls $(\boldsymbol{a}, \boldsymbol{c})$ in both males and females. Scale bar, $2 \mathrm{~mm}$.

Wa-1. These differences persist even after normalized to the total brain volume changes.

The opposite pattern of changes is observed for hippocampal and striatal volumes. Both of these structures are smaller at 3 months but larger at 1 month in $\mathrm{Wa}-1$ compared with the controls (Fig. $5 c, d$ ). Similar to ventricular changes, adult $\mathrm{Wa}-1$ males show greater reduction in hippocampal $(-9 \%)$ and striatal $(-9 \%)$ volumes than adult $W a-1$ females, which show no change in hippocampus and only $4 \%$ reduction in striatum compared with their respective controls. Pubertal changes are similar in both males and females. The reduction in $\mathrm{Wa}-1$ striatal volume persists even after corrected for the total brain volume but not when normalized to the total solid brain volume (i.e., total brain volume without the ventricular mass). These results suggest a correlation between ventricular and striatum volumetric changes.

A simplification of the lateral ventricular shape in pubertal male and female Wa-1 mice compared with their respective controls is detected statistically (combined analyses of Fig. $3 a$ and supplemental Fig. $1 a$, available at www.jneurosci.org as supplemental material). In contrast, at 3 months, Wa-1 males have a larger lateral ventricular surface area than male controls, disproportional to their respective volumetric differences (compare Fig. $3 a$ with supplemental Fig. $1 a$, available at www. jneurosci.org as supplemental material) (see also Fig. 4), indicating an increased convolution of the structure in male $W a-1$ adults compared with the male controls. A lack of changes in the Wa-1 hippocampal and striatal surface areas (supplemental Fig. $2 c, d$, available
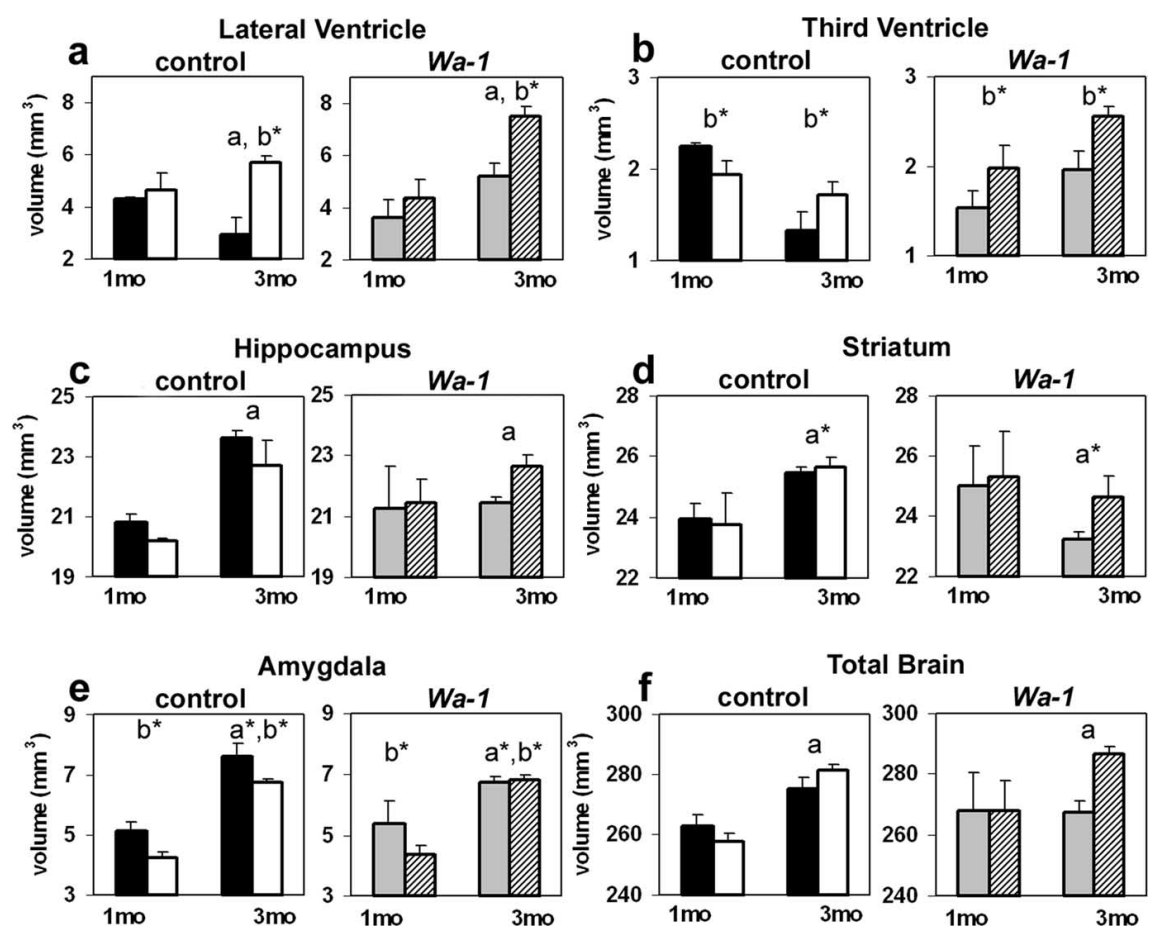

Figure 3. Comparison of forebrain structural volumes. The raw volumetric measurements for male and female control and Wa-1 lateral ventricle $(\boldsymbol{a})$, third ventricle $(\boldsymbol{b})$, hippocampus $(\boldsymbol{c})$, striatum $(\boldsymbol{d})$, amygdala $(\boldsymbol{e})$, and total brain $(\boldsymbol{f})$ are presented. The black bars are control males. The white bars are control females. The gray bars are $W a-1$ males. The diagonally patterned bars are Wa- 1 females. The total brain volume and hippocampus are larger at 3 months than at 1 month for both males and females. The lateral ventricle is enlarged at 3 months compared with 1 month only for females. When males and females are compared, the lateral and third ventricles are lager, whereas the amygdala is smaller in females. Statistical significance is indicated as follows (mean \pm SEM; $p<0.05$ ): $\boldsymbol{a}$, age effect in raw data; $\boldsymbol{b}$, sex effect in raw data; $\boldsymbol{a}^{*}$, age effect normalized to the total brain volume; $\boldsymbol{b}^{*}$, sex effect normalized to the total brain volume. The significance for genotype differences are shown in Figure 5 .

at www.jneurosci.org as supplemental material), despite the altered volumetric measurements (Fig. $5 c, d$ ), suggests shape differences in hippocampus and striatum between control and $\mathrm{Wa}-1$ mice. Interestingly, only adult female $W a-1$ shows comparable hippocampal volume and surface area with that of adult female control. 
a Control Male

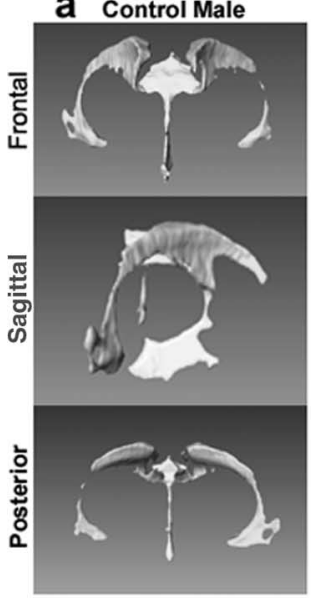

C Control Female

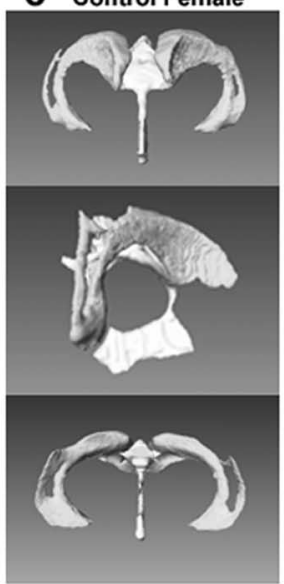

Figure 4. 3D reconstruction of lateral and third ventricles of adult control and Wa- 1 brains. Selected examples of 3D reconstructions of lateral and third ventricles are shown for control male $(\boldsymbol{a})$, Wa-1 male $(\boldsymbol{b})$, control female $(\boldsymbol{c})$, and Wa- 1 female (d), from frontal (top row), sagittal (middle row), and posterior (bottom row) views. The lateral (the 2 crescent structures in gray) and third ventricles (a central structure in white) are enlarged in females $(\boldsymbol{c}, \boldsymbol{d})$ compared with males $(\boldsymbol{a}, \boldsymbol{b})$ in general. The ventricles are larger in Wa-1 than controls in both males (compare $\boldsymbol{a}, \boldsymbol{b}$ ) and females (compare $\boldsymbol{c}, \boldsymbol{d}$ ). An increased convolution of the lateral ventricle in Wa- 1 male $(\boldsymbol{b})$ compared with control male $(\boldsymbol{a})$ is evident.
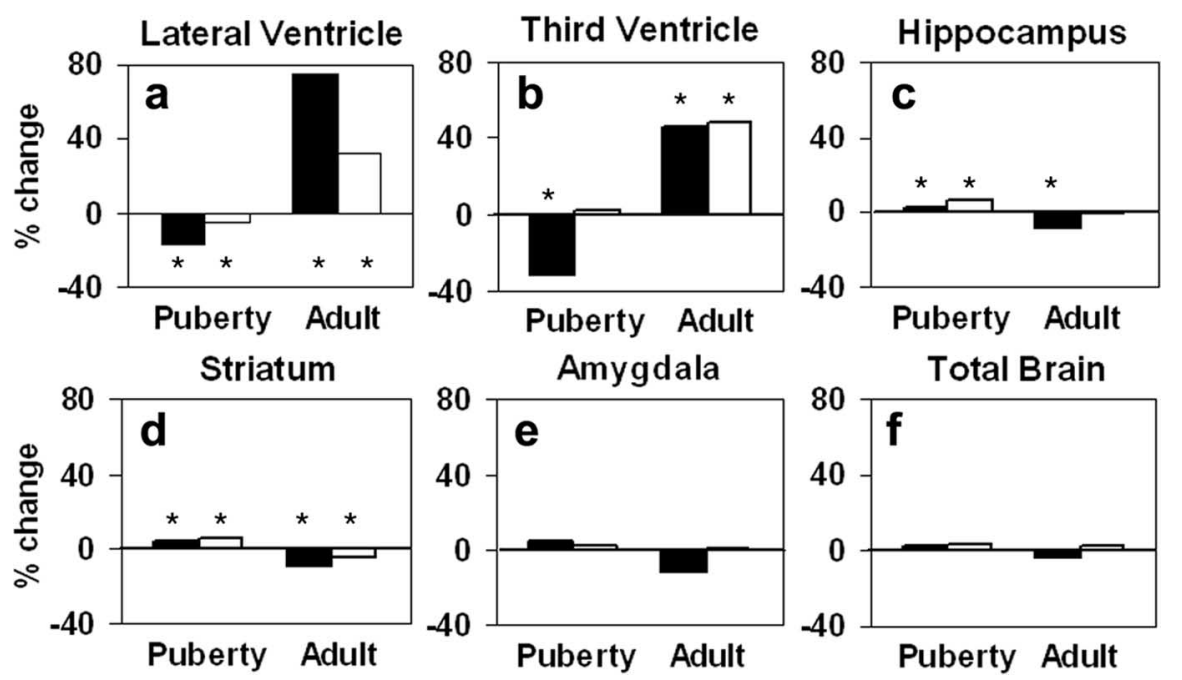

Figure 5. Percentage volumetric changes in Wa-1 forebrain structures compared with controls. Lateral ventricle $(\boldsymbol{a})$, third ventricle $(\boldsymbol{b})$, hippocampus $(\boldsymbol{c})$, striatum $(\boldsymbol{d})$, amygdala $(\boldsymbol{e})$, and total brain $(\boldsymbol{f})$ percentage volumetric changes in Wa-1 compared with their respective controls are shown. The black bars represent males. The white bars represent females. The lateral $(\boldsymbol{a})$ and third $(\boldsymbol{b})$ ventricles are enlarged in the adult. In contrast, the ventricles are reduced in male pubertal Wa- 1 mice compared with the controls, with a corresponding enlargement in hippocampal and striatal volumes. Interestingly, only male adult Wa-1 show reduced hippocampal volume but not female adult Wa-1. Both male and female adults show reduced striatal volumes. Most changes observed are greater in male than in female Wa-1. The asterisks indicate statistically significant $(p<0.05)$ differences between controls and mutants, as determined from raw data. The error bars are not presented here, because these graphs represent percentage change.

Behavior: general motor activity and anxiety assessments

Developmentally, pubertal mice are hypoactive compared with adult mice in general, which is apparent in the reduced total move time $(p=0.018 ; 420.9 \pm 5.0 \mathrm{~s}$ in 1 month vs $436.2 \pm 3.8 \mathrm{~s}$ in 3 months) (Fig. 6a). In addition, the pubertal mice spend more time in the margins of the arena $(p<0.001 ; 456.5 \pm 8.7 \mathrm{~s}$ in 1 month vs $310.6 \pm 6.5 \mathrm{~s}$ in 3 months) (Fig. $6 c$ ) and show greater episodes of stereotypy $(p<0.001 ; 47.5 \pm 1.5 \mathrm{~s}$ in 1 month vs $38.9 \pm 1.1 \mathrm{~s}$ in 3 months) (Fig. $6 e$ ) than their adult counterparts. These findings may reflect a heightened fear or anxiety response to a novel environment in the pubertal mice. In fact, the pubertal
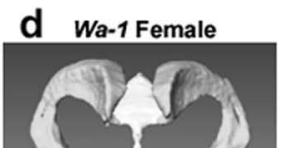

mice show an increased frequency of dark side entries compared with adult mice in general during light/dark choice test (Fig. $6 f$ ), which is another indication of increased anxiety.

When males and females are compared, there are no general differences between the sexes for the total move time, move distance, marginal zone time, and stereotypy (Fig. $6 a-c, e$ ). However, females enter the dark side at a higher frequency than males during light/dark choice test $(p=0.006 ; 17.3 \pm 1.1$ in males vs $21.6 \pm$ 1.1 entries in females) (Fig. $6 f$ ). In adults, males show increased rearing $(p=0.01)$ (Fig. $6 d$ ) and stereotypy movements compared with females $(p=0.007)$ (Fig. 6e). These sex differences are not observed in pubertal mice. These observations indicate that some of the sex-dependent anxietyrelated behaviors do not exist at approximately puberty but can be observed in adulthood.

In addition, when control and $W a-1$ mice are compared, $W a-1$ show hyperactivity compared with controls in both males and females, which is indicated by the increased total move time $(p=0.002$; $418.4 \pm 4.2 \mathrm{~s}$ in control vs $438.7 \pm 4.7 \mathrm{~s}$ in $W a-1)$ (Fig. 6a) and total move distance $(p=0.047 ; 2029.8 \pm 57.7 \mathrm{~cm}$ in control vs $2203.7 \pm 63.7 \mathrm{~cm}$ in $W a-1$ ) (Fig. $7 b$ ) in $W a-1$. This difference is mainly attributable to the control and $W a-1$ behavioral differences in the adult groups and not in the pubertal groups. The total margin time, rearing, stereotypy, and the total dark side entries during light/dark choice test are normal in $\mathrm{Wa}-1$ groups. The hyperactivity in the absence of other anxietyrelated behavioral measures in male and female $W a-1$ may indicate increased exploratory behavior that may be attributable to a reduced fear response to the novel environment.

\section{Delay fear conditioning: \\ training response}

There are no overall differences in the training responses (Fig. $7 a-c$ ) or shock sensitivity between control and $\mathrm{Wa}-1$ mice in pubertal and female groups (data not shown). However, in adult males, $W a-1$ mice show reduced freezing responses during the initial 2 min exploration period $(p=0.037 ; 4.9 \pm 0.7 \%$ in controls vs $2.6 \pm 0.8 \%$ in $W a-1)$ and the second $1 \mathrm{~min}$ exploration period [conditioned response 2 (CR2); $p=0.006$ ] (Fig. $7 b$ ). The general hyperactivity in $\mathrm{Wa}-1$ males has been discussed in the context of open-field activity. These observations indicate that the adult male $\mathrm{Wa}-1$ show reduced fear response to a novel environment and to foot shocks, despite the normal shock sensitivity (data not shown). It is important to note, however, that, at the end of the training (CR3), adult male $W a-1$ show an equivalent freezing response compared 

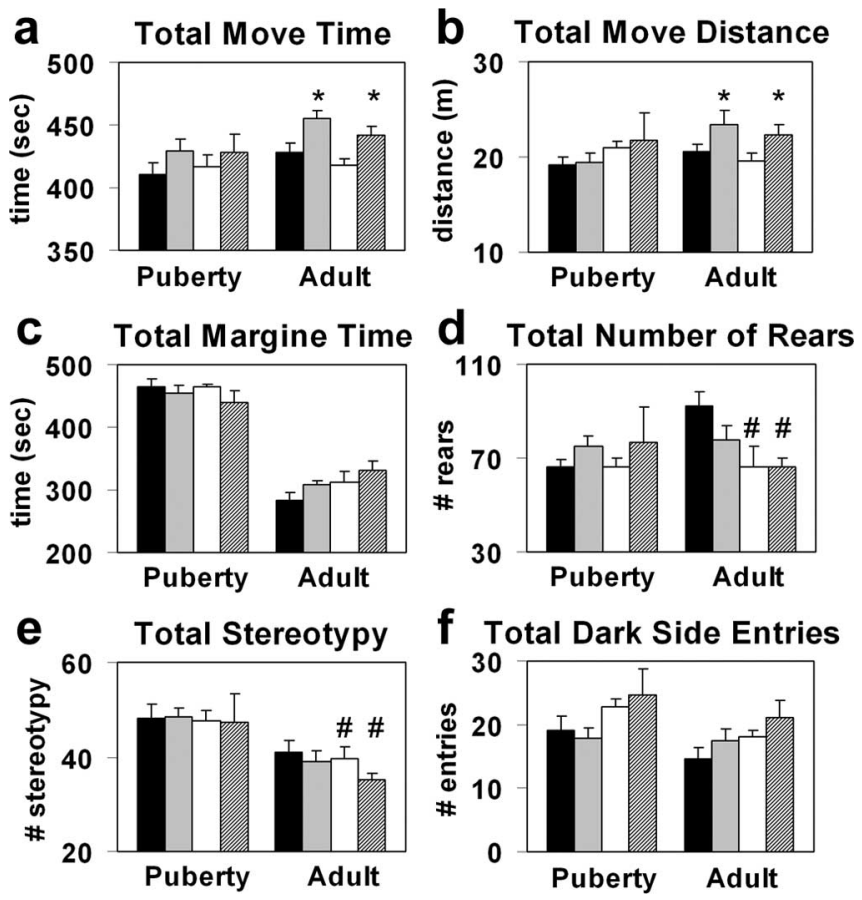

Figure 6. Open-field activity and light/dark choice tests. Total move time $(\boldsymbol{a})$, total move distance $(\boldsymbol{b})$, total marginal zone time $(\boldsymbol{c})$, total number of rears $(\boldsymbol{d})$, total number of stereotypy $(\boldsymbol{e})$, and total number of dark side entries $(\boldsymbol{f})$ are presented. Control males are in black, Wa-1 males are in gray, control females are in white, and $\mathrm{Wa}-1$ females are in a diagonal pattern. Pubertal mice show hypoactivity in the total move time, spend more time in marginal zones, and show increased number of stereotypy episodes, indicating heightened anxiety response compared with adult mice. Females show reduced number of rears and stereotypy, indicative of lower anxiety levels, compared with males. Waved-1 mice show hyperactivity in total move time and distance compared with controls, indicating reduced fear response to novel environment. Statistical significance is indicated as follows (mean $\pm \mathrm{SEM} ; p<0.05$ ): \#, agedependent sex differences; ${ }^{*}$, age-dependent genotype differences. Main age and sex effects (independent of other parameters) are discussed in Results but are not indicated in the figures to simplify the presented data.

with the controls (Fig. $7 b$ ), indicating that the $W a-1$ mice can reach a similar level of fear conditioning as their wild-type counterparts.

\section{Contextual and auditory learning}

A fear conditioning deficit is observed only in adult male $\mathrm{Wa}-1$ mice when compared with adult male controls (Fig. 7e,h). The contextual $(-54 \%)$, pre-tone $(-54 \%)$, and tone $(-44 \%)$ freezing responses are significantly reduced in adult male $\mathrm{Wa}-1 \mathrm{com}-$ pared with the controls $(p=0.001,0.007$, and 0.009 , respectively). When the freezing responses are normalized to the freezing differences during initial 2 min training period, only the context and tone freezing responses are significantly reduced in male $W a-1$ ( $p=0.016$ and 0.002 ). This result indicates that the pre-tone freezing difference is attributable, in part, to the original differences in the general motor activity level. Furthermore, adult Wa-1 male mice show declined tone learning even after the tone freezing response is normalized to the pre-tone freezing differences $(p=0.014)$.

The fear learning impairment is not evident in the pubertal (Fig. $7 d, g$ ) or in female (Fig. $7 f, i) W a-1$, indicating comparable learning abilities between controls and $\mathrm{Wa}-1$ before reaching adulthood and that the learning impairment is not expressed in adult females. These data indicate that the observed learning deficit in $W a-1$ is both sex- and age-dependent.
Stress homeostasis: stress-induced hyperthermia

Because the stress response is an integral part of fear learning, we measured potential stress regulation differences using a stressinduced hyperthermia behavioral paradigm. In general, the baseline stress temperature level (T1) is significantly higher $\left(+1.35^{\circ} \mathrm{C}\right)$ at 1 month compared with 3 months $(p<0.001)$ (Fig. 8 , compare $a, b$ with $c, d$ ), which is in agreement with the general heightened anxiety/fearful state predicted from the open-field activity and light/dark choice tests in pubertal mice. In addition, adult females show a significantly higher $\mathrm{T} 1\left(+0.89^{\circ} \mathrm{C}\right)$ than adult males $(p=0.016$ ) (Fig. 8 , compare $c, d)$. However, no sex difference in $\mathrm{T} 1$ is observed for the pubertal groups. This finding is also in agreement with the previous observations that certain sex-dependent anxiety level differences are apparent only after puberty.

Ten minutes after the acute restraint stress, the stressed temperature level (T2) is higher in pubertal mice than in adult mice $\left(p<0.001 ;+1.41^{\circ} \mathrm{C}\right.$ ) (Fig. 8 , compare $a, b$ with $c, d$ ), but no overall stress response difference $(\mathrm{dT})$ is detected between these two general age groups (Fig. 8e). Similarly, when male and female populations are compared, T2 is elevated in females compared with males in general $\left(p<0.001 ;+0.33^{\circ} \mathrm{C}\right)$ (Fig. 8, compare $a, c$ with $b, d)$. However, there is no sex difference in the dT.

When $W a-1$ and control mice are compared, adult male $W a-1$ mice show a significantly lower T2 than adult male controls (Fig. $8 c$ ). Similarly, dT is reduced in $W a-1$ compared with control in adult males and females (Fig. $8 e$ ). The adult male $W a-1$ mice show a greater reduction in $\mathrm{dT}(-35 \%)$ than the adult female $W a-1(-24 \%)$. Neither T2 nor dT shows genotype dependency at 1 month. These results indicate that the $\mathrm{Wa}-1$ mice have a reduced stress response during adulthood but not during puberty. Furthermore, this blunted stress response is more pronounced in male $W a-1$ than in female $W a-1$. The degree of stress response differences may explain the sex-dependent fear conditioning deficit in the mutants. In fact, the contextual and tone freezing responses are significantly correlated with T2 (Pearson's correlation $=0.764,0.789 ; p<0.0001$ for both) and $\mathrm{dT}$ (Pearson's correlation $=0.556$ and $0.604 ; p=0.02$ and 0.010 , respectively). These findings suggest that the reduced learning ability in $W a-1$ adult males may be attributable, in part, to their reduced stress response. Similarly, lack of a learning deficit in pubertal $W a-1$ male and $W a-1$ females may be attributable to a general enhancement of the stress response in pubertal and female mice, which may have a compensatory effect during stress-dependent learning.

\section{Plasma corticosterone}

To delineate the possible biochemical mechanisms underlying the abnormal stress response in adult $\mathrm{Wa}-1$ mice, plasma corticosterone levels were measured using radioimmunoassay. Corticosterone levels are significantly elevated for both baseline and stressed samples in females compared with males $(p=0.02 ; p<$ 0.001 ) and during puberty compared with adulthood (Fig. $8 f, g$ ). However, the fold increase in stressed over baseline corticosterone levels is the same between males and females, which parallels the behavioral findings in which no difference in stress response (dT) was observed between males and females. No differences are detected between control and $W a-1$ animals.

\section{Plasma catecholamines}

To delineate possible causes for the abnormal behavioral stress response in $W a-1$, plasma catecholamine levels in adult groups were also determined using HPLC. Similar to the plasma cortico- 
Training: Pubertal Males

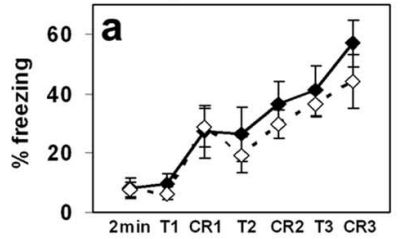

Context Test:

Pubertal Males

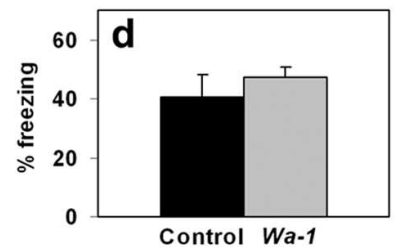

Tone Test: Pubertal Males

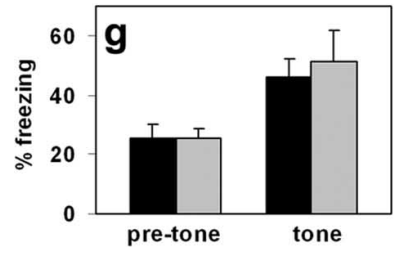

Training: Adult Males

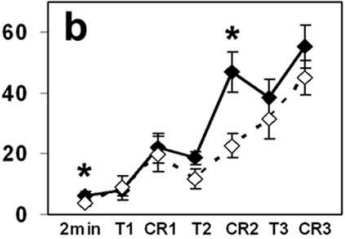

Context Test:

Adult Males

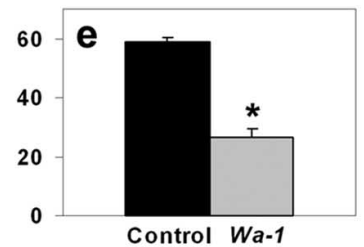

Tone Test: Adult Males

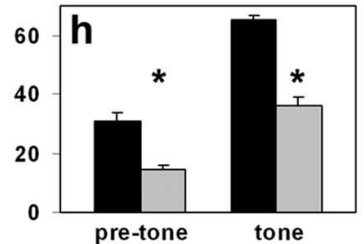

Training: Adult Females

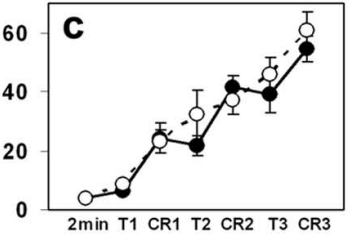

Context Test:

Adult Females

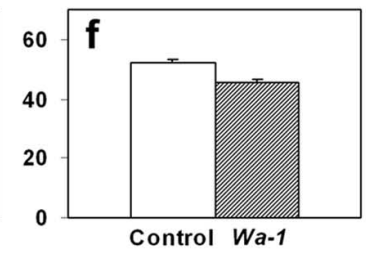

Tone Test: Adult Females

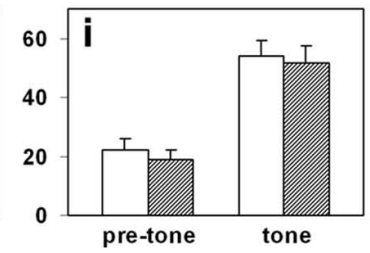

Figure 7. Delay fear conditioning. Freezing responses during training $(\boldsymbol{a}-\boldsymbol{c}), 24 \mathrm{~h}$ context test freezing responses $(\boldsymbol{d}-\boldsymbol{f})$, and $24 \mathrm{~h}$ tone test freezing responses $(\boldsymbol{g}-\boldsymbol{i})$ are shown for pubertal males (left column), adult males (middle column), and adult females (right column). Control males are in solid lines with filled diamonds or in black bars, Wa- 1 males are in dotted lines with open diamonds or in gray bars, control females are in solid lines with filled circles or in white bars, and Wa- 1 females are in dotted lines with open circles or in diagonally patterned bars. Only Wa-1 adult males show a deficit in the CR2, context test, pre-tone, and tone tests. The tone learning is significantly reduced in adult male Wa-1, even after normalized to the reduction in pre-tone freezing. The asterisks indicate statistically significant (mean $\pm \mathrm{SEM} ; p<0.05$ ) differences between control and mutants. T, Tone-shock paired trial; $C R$, conditioned response.
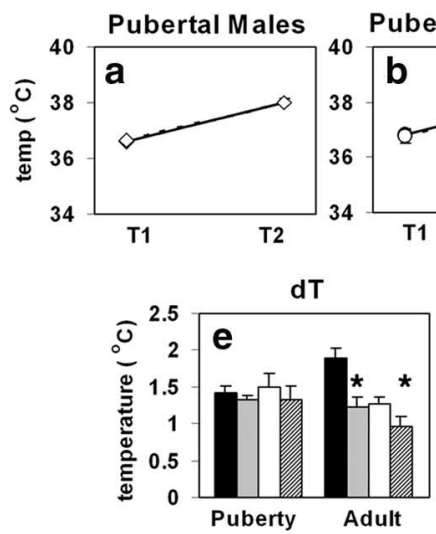
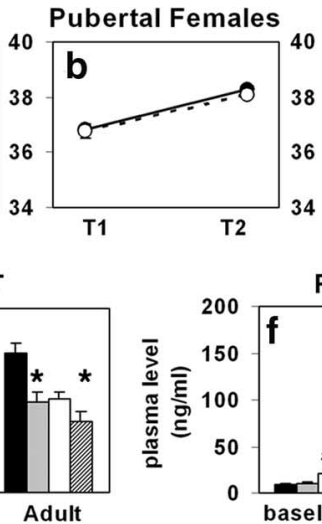

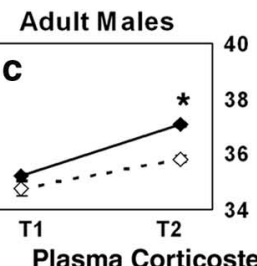

Plasm

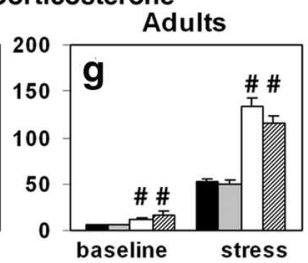

Figure 8. Stress-induced hyperthermia and plasma corticosterone levels. T1 and T2 for pubertal males ( $\boldsymbol{a}$ ), pubertal females $(\boldsymbol{b})$, adult males (c), and adult females (d) are shown. The baseline stress temperature level (T1) and stressed temperature level (T2) is higher in pubertal mice and in females in general. Only adult Wa-1 mice show reduced stress response (dT) compared with their respective control $(\boldsymbol{e})$. The corticosterone levels $(\boldsymbol{f}, \boldsymbol{g})$ parallel the $\mathrm{T} 1$ and $\mathrm{T} 2$ differences between pubertal and adult groups and males and females. However, the stress response difference between Wa- 1 and control mice does not correspond to the corticosterone levels. Control males are in solid lines with filled diamonds or in black bars, Wa- 1 males are in dotted lines with open diamonds or in gray bars, control females are in solid lines with filled circles or in white bars, and $W a-1$ females are in dotted lines with open circles or in diagonally patterned bars. Statistical significance is indicated as follows (mean $\pm \mathrm{SEM} ; p<0.05$ ): *, age-dependent differences between control and mutants; \#, general sex differences (independent of age and genotype). The main age and sex effects are discussed only in Results to simplify the presented data.

sterone result, the plasma NA and A levels are higher in control females than control males ( $p=0.003$ and 0.008 , respectively) (Fig. 9). In female $\mathrm{Wa}-1$, both NA and A levels are reduced compared with the control females ( $p=0.006$ and 0.018 , respec-
Adult Females
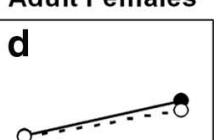

one

tively). However, the A level is elevated, whereas NA level is unchanged in male Wa-1 compared with male control mice ( $p=0.002)$ (Fig. 9). Furthermore, the ratio between NA and $\mathrm{A}$ is the same between control and $W a-1$ females, whereas the ratio is greatly reduced in $W a-1$ compared with control males ( $p=0.033$ ).

\section{Discussion}

Stress responsiveness as a correlate of learning in $W a-1$

The stress response and fear learning impairments in $\mathrm{Wa}-1$ occur predominantly in males and after pubertal onset. In fact, we observed fear learning impairment only in adult $\mathrm{Wa}-1$ males. This learning deficit may be attributable, in part, to the abnormalities during the acquisition of fear (a reduced freezing response during CR2). Because $\mathrm{Wa}-1$ mice, in general, exhibited hyposensitivity to stress, neither the novel training environment nor the foot shocks during the training period may be as salient for $W a-1$ mice as for the control mice. Thus, the observed sex difference in learning in Wa-1 mice may be partly attributable to a greater suppression of stress response in male $\mathrm{Wa}-1$ than female $\mathrm{Wa}-1$ compared with their respective controls, which suggests that a threshold stress response must be achieved for comparable fear learning. Interestingly, female rats, in general, appear less sensitive than males to the impairing effects of stress and show enhanced performance after the stress duration that induces impairments in males (Luine et al., 1994; Bowman et al., 2001; Luine, 2002). Therefore, the sexdependent penetrance of the mutant behavioral phenotype reported here may be partly attributable to the general sex differences in stress compensatory mechanisms and stress-dependent learning behaviors. In fact, the $T G F \alpha$ transcript levels in stressregulating structures, such as hypothalamus, pituitary, and adrenal, and memoryassociated structures, such as hippocampus and amygdala, show sex and age specificity in both control and Wa-1 mice (Koshibu and Levitt, 2005). Such differences could contribute to the distinct sex-dependent compensatory mechanisms for the genetic mutation observed here.

Interestingly, our stress response findings in the male adult $W a-1$ are inversely correlated with the previous findings in which $T G F \alpha$ overexpressing transgenic mice on a CD1 strain exhibited hypersensitivity to stress (Hilakivi-Clarke et al., 1992, 1993). A lack of impairment reported in other anxiety tests, such as elevated plus maze, voluntary alcohol intake (HilakiviClarke et al., 1992), and light/dark choice test (this study), indi- 


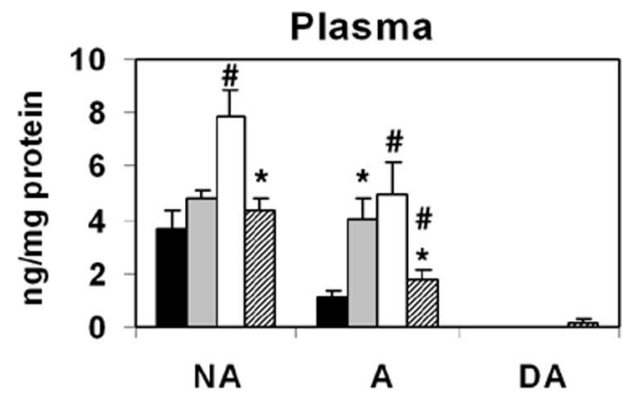

Figure 9. Plasma catecholamine levels. Female controls show higher plasma NA and A levels than control males and Wa-1 females. In contrast, male Wa-1 mice show higher plasma A concentration than control males. Dopamine is virtually undetectable in any of the groups. Control males are in black, Wa-1 males are in gray, control females are in white, and Wa-1 females are in diagonal pattern. DA, Dopamine. Statistical significance is indicated as follows (mean \pm SEM; $p<0.05$ ): *, sex-dependent differences between control and Wa-1; \#, genotype-dependent differences between males and females.

cates the specificity of anxiety and stress systems regulated by TGF $\alpha$, particularly in males. Consistent with this view, we found no differences in plasma corticosterone levels between the control and $W a-1$ mice. However, there were differences in plasma A concentration in both male and female $W a-1$ and plasma NA concentration in female $W a-1$ compared with their respective controls. These results indicate that the behavioral abnormalities associated with $\mathrm{Wa}-1$ mice may involve adrenal medulla and sympathetic systems.

The fact that the pubertal $W a-1$ mice do not show a learning deficit is not surprising, because there are no differences in stress or fear responses in pubertal mutants compared with the controls. The late onset of learning and stress response changes in $W a-1$ may be attributable to the relative hypersensitivity to stress in pubertal mice compared with adult mice as discussed below. If the behavioral deficit in adult $\mathrm{Wa}-1$ is, in fact, attributable to the reduced fear and stress responses, then a general increase in the fear and anxiety levels in pubertal mice may mask the mutant behavioral phenotype during puberty.

\section{Anatomical correlates of stress and learning impairments in $W a-1$}

The enlargement of lateral ventricles and the reduction of hippocampus and striatum parallel several behavioral findings in the Wa-1 mice. These changes are uniquely expressed in adults, when the behavioral abnormalities are observed, and preferentially in males. In particular, the reduced hippocampal volume was only observed in male and not in female adult $W a-1$. Because the hippocampus is involved in both stress regulation and fear learning (Radulovic et al., 1999; Roozendaal et al., 1999), the adult male-specific hippocampal alteration may, in part, underlie the pronounced stress and fear learning deficits in male $\mathrm{Wa}-1$ mice. Interestingly, modest differences in hippocampal volume and shape distortions also have been reported in subjects with schizophrenia (Csernansky et al., 1998; Narr et al., 2001).

In pubertal mice, although some minor forebrain structural changes were observed in $\mathrm{Wa}-1$ mice compared with control mice, no behavioral abnormalities were detected. This unique finding indicates that brain anatomical changes may precede the development of behavioral deficits later in life.

To delineate the possible involvement of gonadal steroids in producing the observed $\mathrm{Wa}-1$ phenotypes, gonadectomy was conducted at approximately the onset of puberty (postnatal days 26-30), before detection of a behavioral phenotype. However, the interpretation of this experiment was complicated because the sham surgery alone eliminated the differences in stress response and fear conditioning between control and $\mathrm{Wa}-1$ in both male and female adult mice (K. Koshibu and P. Levitt, unpublished observations). Additional experiments to manipulate gonadal hormones at earlier ages would be interesting, because minor anatomical changes are already present at puberty. Our TGF $\alpha$ and epidermal growth factor receptor mRNA expression studies indicate that surgeries done at 1 or 2 postnatal weeks (when we saw maximum expression of these transcripts in some structures) would be reasonable time points for further investigating the involvement of gonadal steroid in regulating sex- and age-dependent behavioral and anatomical differences in control and $W a-1$ mice.

\section{Attribution of the $W a-1$ phenotype to TGF $\alpha$}

The enlarged ventricles and contextual fear conditioning deficit observed in adult $\mathrm{Wa}-1$ males are in agreement with our previous study (Burrows et al., 2000). However, there are a few discrepancies between Burrows et al. (2000) and our current study, which may be attributable to strain and gene mutation differences. There are numerous studies indicating differential effects of strains on behavior (Alexander et al., 1996; Homanics et al., 1999; Rogers et al., 1999; Avgustinovich et al., 2000; Bolivar et al., 2000) and strain-dependent knock-out phenotypes (for review, see Gingrich and Hen, 2000). Therefore, the difference between our previous and current studies may be partly attributable to their strain background differences. It also is important to emphasize that the original strain of $\mathrm{Wa}-1$ possessed additional mutations (APB/Le a/a Tyrpl ${ }^{\mathrm{b}} / \mathrm{Tyrpl}^{\mathrm{b}}$ bt/bt p/p Bmp5 $5^{\mathrm{SE}} / \mathrm{Bmp} 5^{\mathrm{SE}}$ ) and that, in this study, the brain anatomy and fear conditioning characterization was achieved using more current methods. These factors also could have contributed to the apparent differences in our studies.

Interestingly, $T G F \alpha$ knock-out mice on a congenic C57BL/6J background do not express the behavioral or anatomical phenotypes evident in the Wa-1 mice of either background strain (Burrows et al., 2000). We conclude that the failure of constitutive elimination of TGF $\alpha$ gene to produce a CNS phenotype is likely to be attributable to different compensatory mechanisms invoked in the hypomorphic $W a-1$ strain compared with the full null strain.

\section{General sex- and age-dependent features}

Some of our general age- and sex-mediated behavioral and anatomical findings correlate well with human findings. For example, the observed hypersensitivity to stress in pubertal mice is in agreement with the previous findings in humans (Allen and Matthews, 1997) and in rodents (Walker et al., 1995; Hascoet et al., 1999). In addition, sex-dependent stress regulation was observed mainly in adult mice and not in pubertal mice, indicating that certain stress regulation systems mature during and/or after puberty in a sex-dependent manner (Ramaley, 1972; Gabriel et al., 1992; Spinedi et al., 1997).

Interestingly, despite these age- and sex-dependent differences in anxiety and stress responses, no fear learning differences were observed among the control mice. These findings may indicate that, under normal circumstances, the different sensitivity to stress in males and females, at different developmental stages, is compensated to the same level during fear learning. When a genetic mutation is introduced, however, the compensatory mechanisms are disturbed, resulting in sex- and age-dependent stressmediated learning impairments in mutants. The implications of 
these findings are that susceptibility to specific gene mutations and the expression of affected phenotypes are sex dependent. The reported differences between sexes in the disruption of cognition and behavior in neuropsychiatric and developmental disorders are consistent with this hypothesis (Nopoulos et al., 1997; Nagy et al., 2001; Gur et al., 2004).

The anatomical analyses revealed that both pubertal and female mice show reduced amygdala volume compared with adult and male mice, respectively. These age- and sex-associated amygdala changes appear to be phylogenetically conserved, paralleling reports in humans (Filipek et al., 1994; Giedd et al., 1997; Goldstein et al., 2001). Because the amygdala is a well known structure associated with emotion, our findings may reflect developmental maturation and sexual differentiation of amygdala-related functions, such as stress and anxiety.

\section{Conclusion}

Structural and functional human neuroimaging studies are being combined with endophenotype and genotype analyses to directly address structure-function relationships in neuropsychiatric diseases (for review, see Hariri and Weinberger, 2003; Mattay and Goldberg, 2004). The present study in mice highlights the phylogenetic conservation of fundamental differences between brain structure-function relationships in the context of sex-dependent penetration of neurological disorders, reflecting selective and complex regulation of brain development during puberty.

\section{References}

Alexander RC, Wright R, Freed W (1996) Quantitative trait loci contributing to phencyclidine-induced and amphetamine-induced locomotor behavior in inbred mice. Neuropsychopharmacology 15:484-490.

Allen MT, Matthews KA (1997) Hemodynamic responses to laboratory stressors in children and adolescents: the influences of age, race, and gender. Psychophysiology 34:329-339.

Avgustinovich DF, Lipina TV, Bondar NP, Alekseyenko OV, Kudryavtseva NN (2000) Features of the genetically defined anxiety in mice. Behav Genet 30:101-109.

Berkowitz EA, Seroogy KB, Schroeder JA, Russell WE, Evans EP, Riedel RF, Phillips HK, Harrison CA, Lee DC, Luetteke NC (1996) Characterization of the mouse transforming growth factor alpha gene: its expression during eyelid development and in waved 1 tissues. Cell Growth Differ 7:1271-1282.

Bolivar VJ, Caldarone BJ, Reilly AA, Flaherty L (2000) Habituation of activity in an open field: a survey of inbred strains and F1 hybrids. Behav Genet 30:285-293.

Bowman RE, Zrull MC, Luine VN (2001) Chronic restraint stress enhances radial arm maze performance in female rats. Brain Res 904:279-289.

Bowman RE, Beck KD, Luine VN (2003) Chronic stress effects on memory: sex differences in performance and monoaminergic activity. Horm Behav 43:48-59.

Burrows RC, Levitt P, Shors TJ (2000) Postnatal decrease in transforming growth factor alpha is associated with enlarged ventricles, deficient amygdaloid vasculature and performance deficits. Neuroscience 96:825-836.

Campbell DB, Hess EJ (1997) Rapid genotyping of mutant mice using dried blood spots for polymerase chain reaction (PCR) analysis. Brain Res Brain Res Protoc 1:117-123.

Campbell DB, North JB, Hess EJ (1999) Tottering mouse motor dysfunction is abolished on the Purkinje cell degeneration (pcd) mutant background. Exp Neurol 160:268-278.

Caviness Jr VS, Kennedy DN, Richelme C, Rademacher J, Filipek PA (1996) The human brain age 7-11 years: a volumetric analysis based on magnetic resonance images. Cereb Cortex 6:726-736.

Chetelat G, Baron JC (2003) Early diagnosis of Alzheimer's disease: contribution of structural neuroimaging. NeuroImage 18:525-541.

Crew FAE (1933) Waved: an autosomal recessive coat form character in the mouse. J Genet 27:95-96.

Csernansky JG, Joshi S, Wang L, Haller JW, Gado M, Miller JP, Grenander U, Miller MI (1998) Hippocampal morphometry in schizophrenia by high dimensional brain mapping. Proc Natl Acad Sci USA 95:11406-11411.
Filipek PA, Richelme C, Kennedy DN, Caviness Jr VS (1994) The young adult human brain: an MRI-based morphometric analysis. Cereb Cortex 4:344-360.

Fowler KJ, Mann GB, Dunn AR (1993) Linkage of the murine transforming growth factor alpha gene with Igk, Ly-2, and Fabp1 on chromosome 6. Genomics 16:782-784.

Gabriel SM, Roncancio JR, Ruiz NS (1992) Growth hormone pulsatility and the endocrine milieu during sexual maturation in male and female rats. Neuroendocrinology 56:619-625.

Giedd JN, Castellanos FX, Rajapakse JC, Vaituzis AC, Rapoport JL (1997) Sexual dimorphism of the developing human brain. Prog Neuropsychopharmacol Biol Psychiatry 21:1185-1201.

Gingrich JA, Hen R (2000) The broken mouse: the role of development, plasticity and environment in the interpretation of phenotypic changes in knockout mice. Curr Opin Neurobiol 10:146-152.

Goldstein JM, Seidman LJ, Horton NJ, Makris N, Kennedy DN, Caviness Jr VS, Faraone SV, Tsuang MT (2001) Normal sexual dimorphism of the adult human brain assessed by in vivo magnetic resonance imaging. Cereb Cortex 11:490-497.

Gur RE, Kohler C, Turetsky BI, Siegel SJ, Kanes SJ, Bilker WB, Brennan AR, Gur RC (2004) A sexually dimorphic ratio of orbitofrontal to amygdala volume is altered in schizophrenia. Biol Psychiatry 55:512-517.

Hariri AR, Weinberger DR (2003) Imaging genomics. Br Med Bull 65:259-270.

Hascoet M, Colombel MC, Bourin M (1999) Influence of age on behavioural response in the light/dark paradigm. Physiol Behav 66:567-570.

Hilakivi-Clarke LA, Arora PK, Sabol MB, Clarke R, Dickson RB, Lippman ME (1992) Alterations in behavior, steroid hormones and natural killer cell activity in male transgenic TGF alpha mice. Brain Res 588:97-103.

Hilakivi-Clarke LA, Arora PK, Clarke R, Wright A, Lippman ME, Dickson RB (1993) Opposing behavioural alterations in male and female transgenic TGF alpha mice: association with tumour susceptibility. Br J Cancer 67:1026-1030.

Homanics GE, Quinlan JJ, Firestone LL (1999) Pharmacologic and behavioral responses of inbred C57BL/6J and strain 129/SvJ mouse lines. Pharmacol Biochem Behav 63:21-26.

Koshibu K, Levitt P (2005) Comparative sex differences in expression of transforming growth factor-alpha and epidermal growth factor receptor mRNA in Waved-1 and $\mathrm{C} 57 \mathrm{Bl}^{6}$ mice. Neuroscience, in press.

Koshibu K, Levitt P, Ahrens ET (2004) Sex-specific, postpuberty changes in mouse brain structures revealed by three-dimensional magnetic resonance microscopy. NeuroImage 22:1636-1645.

Lewis DA, Lieberman JA (2000) Catching up on schizophrenia: natural history and neurobiology. Neuron 28:325-334.

Lindsey JW, Jung AE, Narayanan TK, Ritchie GD (1998) Acute effects of a bicyclophosphate neuroconvulsant on monoamine neurotransmitter and metabolite levels in the rat brain. J Toxicol Environ Health A 54:421-429.

Luetteke NC, Qiu TH, Peiffer RL, Oliver P, Smithies O, Lee DC (1993) TGF alpha deficiency results in hair follicle and eye abnormalities in targeted and waved-1 mice. Cell 73:263-278.

Luetteke NC, Phillips HK, Qiu TH, Copeland NG, Earp HS, Jenkins NA, Lee DC (1994) The mouse waved-2 phenotype results from a point mutation in the EGF receptor tyrosine kinase. Genes Dev 8:399-413.

Luine V (2002) Sex differences in chronic stress effects on memory in rats. Stress 5:205-216.

Luine V, Villegas M, Martinez C, McEwen BS (1994) Repeated stress causes reversible impairments of spatial memory performance. Brain Res 639:167-170.

Ma YJ, Junier MP, Costa ME, Ojeda SR (1992) Transforming growth factoralpha gene expression in the hypothalamus is developmentally regulated and linked to sexual maturation. Neuron 9:657-670.

Ma YJ, Costa ME, Ojeda SR (1994a) Developmental expression of the genes encoding transforming growth factor alpha and its receptor in the hypothalamus of female rhesus macaques. Neuroendocrinology 60:346-359.

Ma YJ, Dissen GA, Merlino G, Coquelin A, Ojeda SR (1994b) Overexpression of a human transforming growth factor-alpha (TGF alpha) transgene reveals a dual antagonistic role of TGF alpha in female sexual development. Endocrinology 135:1392-1400.

MacQueen GM, Campbell S, McEwen BS, Macdonald K, Amano S, Joffe RT, Nahmias C, Young LT (2003) Course of illness, hippocampal function, and hippocampal volume in major depression. Proc Natl Acad Sci USA 100:1387-1392. 
Mann GB, Fowler KJ, Gabriel A, Nice EC, Williams RL, Dunn AR (1993) Mice with a null mutation of the TGF alpha gene have abnormal skin architecture, wavy hair, and curly whiskers and often develop corneal inflammation. Cell 73:249-261.

Mattay VS, Goldberg TE (2004) Imaging genetic influences in human brain function. Curr Opin Neurobiol 14:239-247.

Mefford IN (1985) Biomedical uses of high-performance liquid chromatography with electrochemical detection. Methods Biochem Anal 31:221-258.

Nagy E, Loveland KA, Orvos H, Molnar P (2001) Gender-related physiologic differences in human neonates and the greater vulnerability of males to developmental brain disorders. J Gend Specif Med 4:41-49.

Narr KL, Thompson PM, Sharma T, Moussai J, Blanton R, Anvar B, Edris A, Krupp R, Rayman J, Khaledy M, Toga AW (2001) Three-dimensional mapping of temporo-limbic regions and the lateral ventricles in schizophrenia: gender effects. Biol Psychiatry 50:84-97.

Nopoulos P, Flaum M, Andreasen NC (1997) Sex differences in brain morphology in schizophrenia. Am J Psychiatry 154:1648-1654.

Radulovic J, Ruhmann A, Liepold T, Spiess J (1999) Modulation of learning and anxiety by corticotropin-releasing factor (CRF) and stress: differential roles of CRF receptors 1 and 2. J Neurosci 19:5016-5025.

Ramaley JA (1972) Changes in daily serum corticosterone values in maturing male and female rats. Steroids 20:185-197.

Rogers DC, Jones DN, Nelson PR, Jones CM, Quilter CA, Robinson TL, Hagan JJ (1999) Use of SHIRPA and discriminant analysis to characterise marked differences in the behavioural phenotype of six inbred mouse strains. Behav Brain Res 105:207-217.

Roozendaal B, Nguyen BT, Power AE, McGaugh JL (1999) Basolateral amygdala noradrenergic influence enables enhancement of memory consolidation induced by hippocampal glucocorticoid receptor activation. Proc Natl Acad Sci USA 96:11642-11647.

Rutter M, Caspi A, Moffitt TE (2003) Using sex differences in psychopathology to study causal mechanisms: unifying issues and research strategies. J Child Psychol Psychiatry 44:1092-1115.

Spinedi E, Chisari A, Pralong F, Gaillard RC (1997) Sexual dimorphism in the mouse hypothalamic-pituitary-adrenal axis function after endotoxin and insulin stresses during development. Neuroimmunomodulation 4:77-83.

Walker CD, Trottier G, Rochford J, Lavallee D (1995) Dissociation between behavioral and hormonal responses to the forced swim stress in lactating rats. J Neuroendocrinol 7:615-622.

Weber B, Collins C, Robbins C, Magenis RE, Delaney AD, Gray JW, Hayden MR (1990) Characterization and organization of DNA sequences adjacent to the human telomere associated repeat (TTAGGG)n. Nucleic Acids Res 18:3353-3361.

Weber JL (1990) Human DNA polymorphisms and methods of analysis. Curr Opin Biotechnol 1:166-171.

Weickert CS, Blum M (1995) Striatal TGF-alpha: postnatal developmental expression and evidence for a role in the proliferation of subependymal cells. Brain Res Dev Brain Res 86:203-216.

Weinberger DR (1995) From neuropathology to neurodevelopment. Lancet 346:552-557.

Zethof TJ, Van der Heyden JA, Tolboom JT, Olivier B (1994) Stressinduced hyperthermia in mice: a methodological study. Physiol Behav 55:109-115. 